\title{
Big things in Little Ones: an Original Study
}

\author{
Nusrat Nazir*1 and Altaf Hussain Chalkoo ${ }^{2}$ \\ ${ }^{1}$ Post Graduate Student Department of Oral Medicine and Radiology, India \\ ${ }^{2}$ Professor and HOD Department of oral medicine and radiology, GDC srinagar, India
}

Received: May 15, 2018; Published: May 31, 2018

*Corresponding author: : Nusrat Nazir, Post graduate student, Department of Oral Medicine and Radiology GDC Srinagar, Kashmir, Jammu \& Kashmir, India

\section{Introduction}

Pediatric dentistry is an age-defined specialty that provides both primary and comprehensive preventive and therapeutic oral health care for infants and children through adolescence, including those with special health care needs. Pediatric care is actually a multidisciplinary treatment approach which include;

a. Pediatric dentists.

b. General dental practitioners and other dental specialists.

c. Physicians and other health care providers.

d. Government agencies and health care policy makers.

e. Individuals interested in the oral health of children [1].

Rare diseases are a group of more than 5000 diseases that account for $10 \%$ of human disease [2-4]. In the last decades the attention of several disciplines of medicine have been focused on rare diseases; rare diseases are estimated to be 5000 , and every week 5 new rare diseases are considered as new findings hence the number of these diseases is enormously increasing. In this articles we will be discussing all the rare cases and some less common cases that were referred to our department for evaluation and diagnosis.

\section{Methodology}

This prospective cohart study was conducted in the department of oral medicine and radiology government dental college Srinagar. Pediatric patients with some rare diseases /syndromes or complicated conditions were selected from the outpatient clinic over a period of 1 year [2016]. A detailed history and examination were taken with emphasis on chief complaint and its duration, general health of the patient, past medical history, and oral hygiene status. A thorough clinical examination was carried out in all patients pertaining to the type of disorder they were suffering. Appropriate investigations were done in all the cases to reach to a final diagnosis.

\section{Statistical Analysis}

Statistical software SPSS (version 20.0) and Microsoft Excel were used to carry out the statistical analysis of data. Data was presented by means of bar charts and the pie diagrams.

\section{Results}

A total of 35 patients with some special findings were included in the study. There were 17 males and 18 females. Following cases were seen during the period of one year (Table 1).

Table 1.

\begin{tabular}{|c|l|}
\hline Ectodermal dysplasia & $\mathbf{4}$ \\
\hline Ichthyosis & 1 \\
\hline Firomatosis gingivae & 3 \\
\hline pleomorphic adenoma & 4 \\
\hline hypoplasictic condyle & 1 \\
\hline epidermolysis bulosa & 1 \\
\hline cleft lip+palate & 5 \\
\hline cleft palate & 6 \\
\hline amelogenesis imperfect & 3 \\
\hline dentinogenesis imperfecta & 2 \\
\hline lymphangioma tongue & 1 \\
\hline selective Ig A deficiency & 1 \\
\hline
\end{tabular}

\section{Discussion}

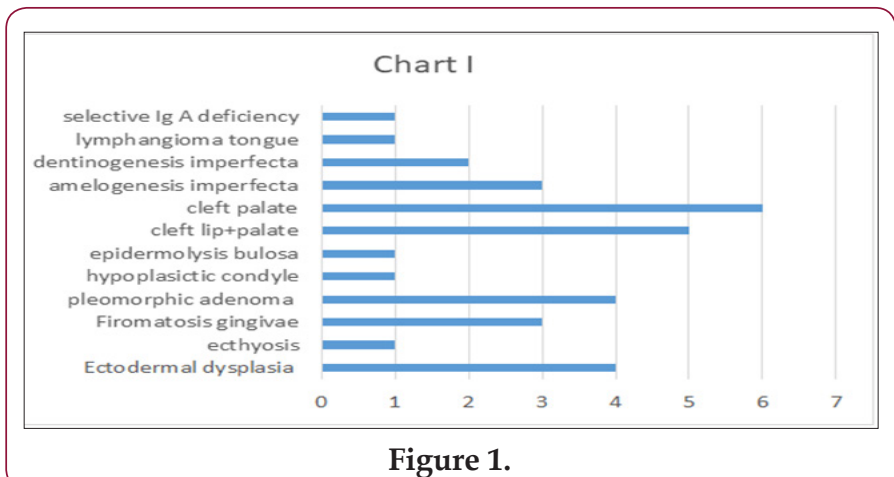

In the discussion each condition is briefly described followed by the pictures of the cases. Pleomorphic adenoma is called as "mixed tumor" because it has both epithelial and connective tissue elements. It commonly affects parotid gland followed by minor salivary glands. About 450-750 minor salivary glands are present 
in the head and neck region. Highest concentration of these minor salivary glands has been described on the palate, particularly the junction of hard and soft palate. Most common minor salivary gland tumors occur at this site [5]. In all 8-10\% of salivary gland tumors arise in the palate. These tumors are malignant in $40-82 \%$ of cases [6-9]. There were 4 case of pleomorphic adenoma which came to our department diagnosed by FNAC and USG. Three were present on palate and one in submandibular region (Figures 1-4).
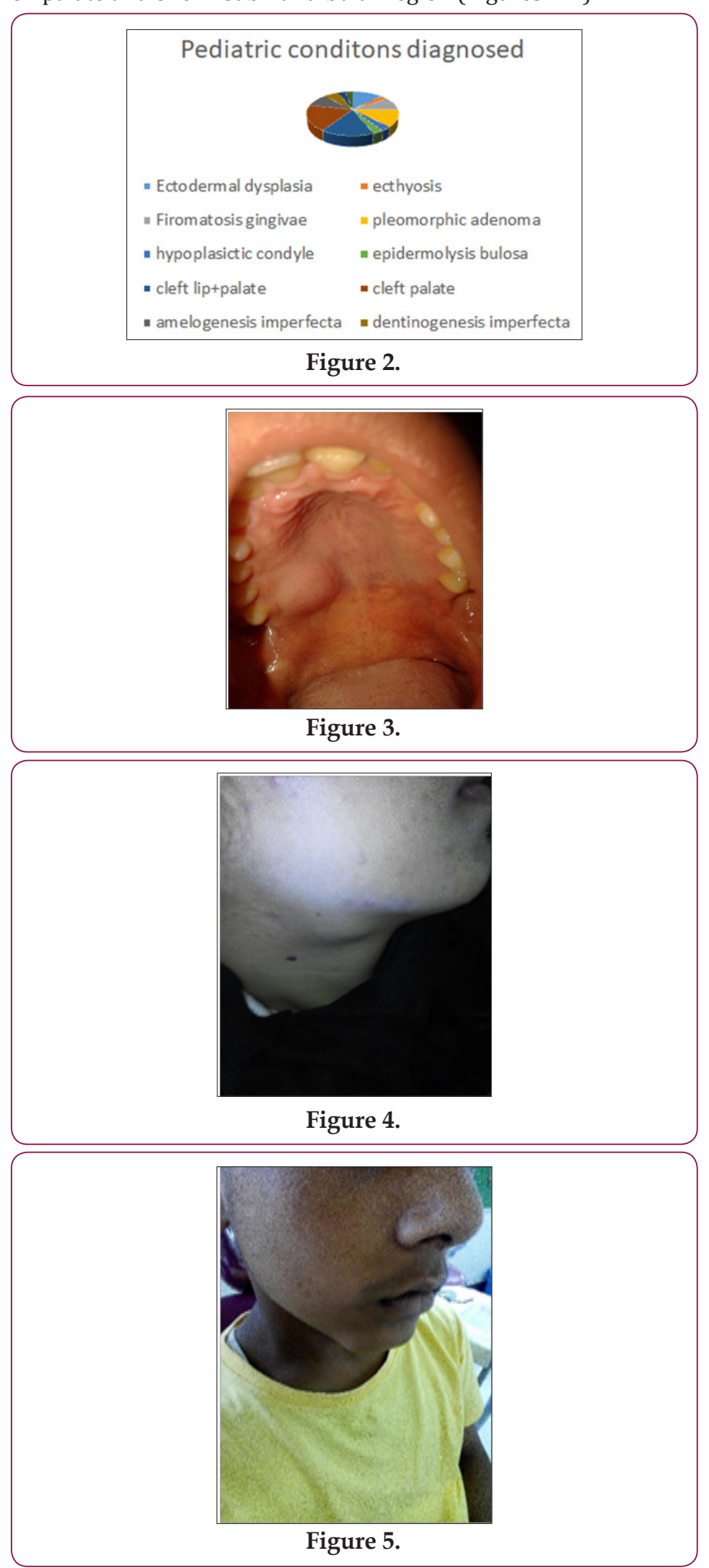

Fibrous dysplasia (FD) is a bone development anomaly characterized by hamartoma proliferation of fibrous tissue within the medullary bone, with secondary bony metaplasia, producing immature, newly formed and weakly calcified bone, without maturation of the osteoblast which appears radiolucent on radiographs, with the classically described ground-glass appearance [10]. One such case was seen with involvement of mandible Figure 5 showing enlargement of chin and Figure 6 showing CBCT image of same patient.

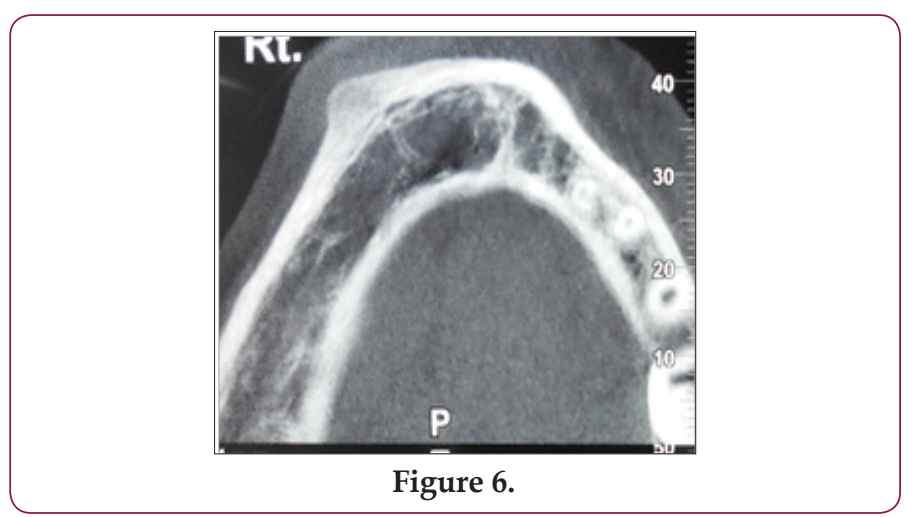

Epidermolysis Bullosa (EB) is a group of rare inherited disorders, usually detected at birth or early childhood. This dermatological condition is a severe autoimmune disease [11-12]. Scarring of the extensor surfaces of the extremities, hands and feet are typical; milia occur frequently; and nails often become thick and dystrophic or are lost. The disorder affects both sexes equally and occurs in all racial and ethnic groups [13]. Figure 7 showing crustation of lips and Figure 8 is showing severe skin involvement and missing nails. Ichthyosis forms clinically and etiologically a large heterogeneous group of cornification disorders that are characterized by accumulation of hyperkeratotic scales on the skin surface [14,15]. Ichthyosis is derived from the Greek word "ikhthus" meaning "fish" and refers to the similarity in appearance of skin to fish scales. Ichthyosis is caused by abnormality in keratinization and exfoliation of the horny cell layer [16]. The relevant clinical feature of this disorder is scaling and thickening of cornified layer which is often accompanied by inflammation of the skin presenting itself as erythroderma [17]. (Figures 9-11) is showing the involvement of face legs and arms. There was genralised cornification of whole body in this patient.

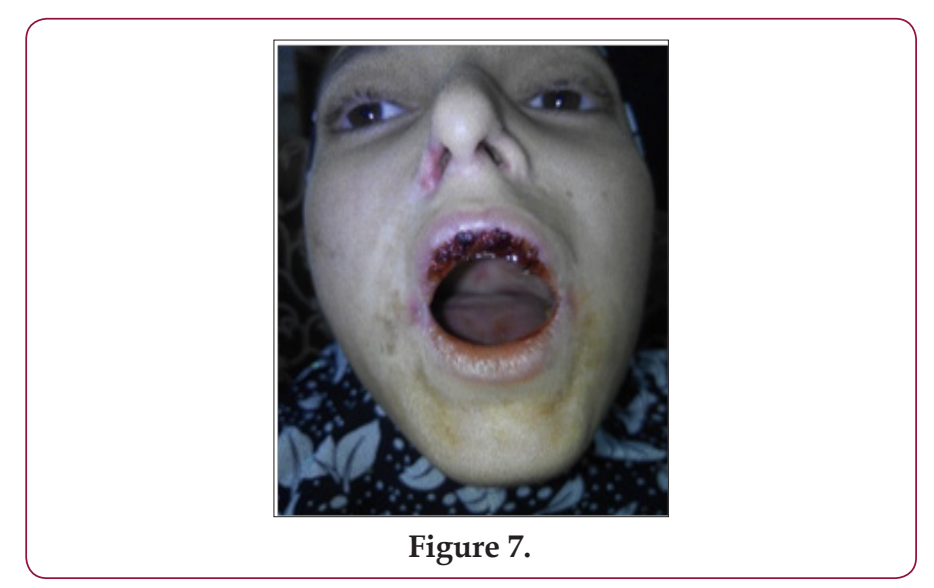




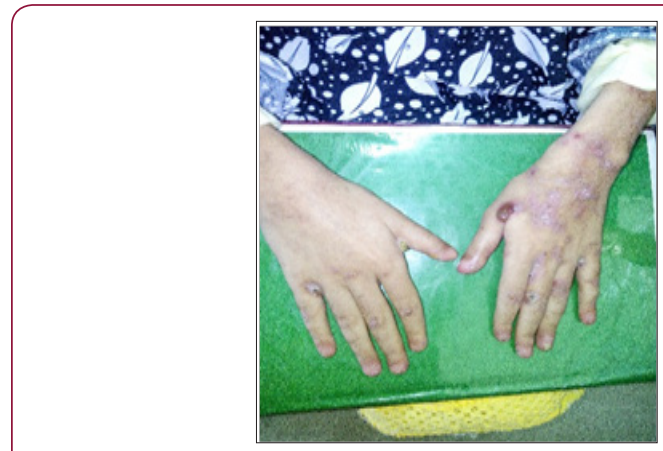

Figure 8.

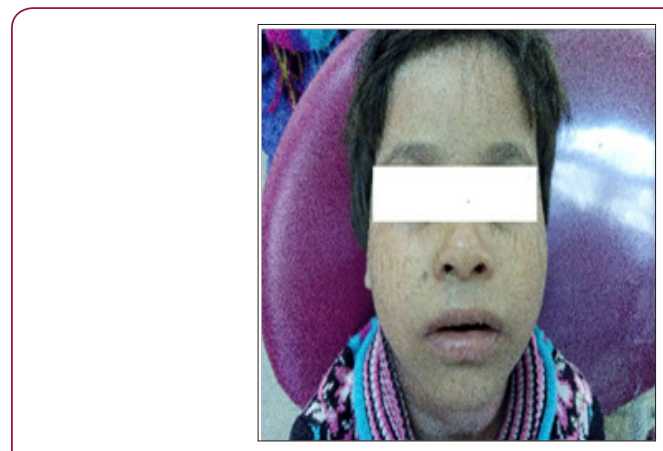

Figure 9.

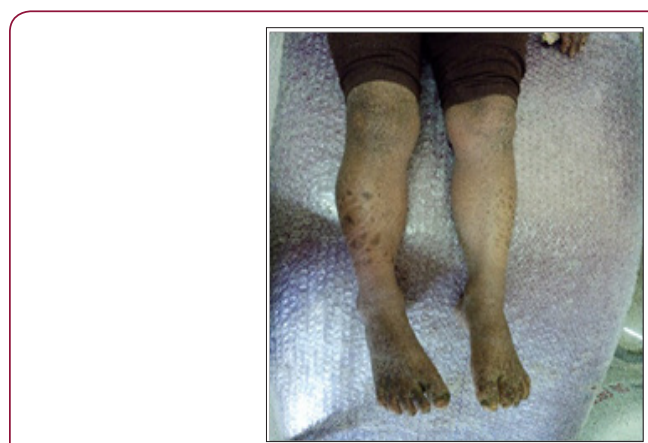

Figure 10.

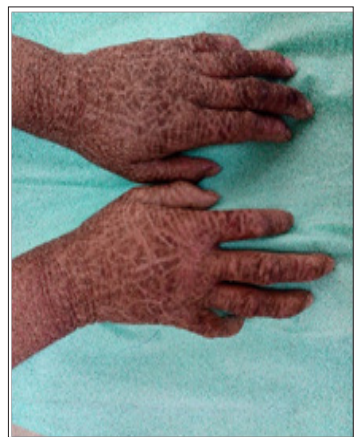

Figure 11.

Ectodermal dysplasia, as first described by Thurman, is a hereditary disorder occurring as a consequence of disturbances in the ectoderm of the developing embryo. The triad of nail dystrophy (onchodysplasia), alopecia or hypotrichosis (scanty, fine light hair on the scalp and eyebrows), and palmoplantar hyperkeratosis is usually accompanied by a lack of sweat glands (hypohidrosis) and a partial or complete absence of primary and/or permanent denti- tion [18-21]. (Figures 12-14) is showing hypotrichosis, onchodysplasia and oligodontia respectively. (Figures 15-18) are the cases of cleft lip, cleft palate, lymphangioma of tongue and fibromatosis gingivae respectively.

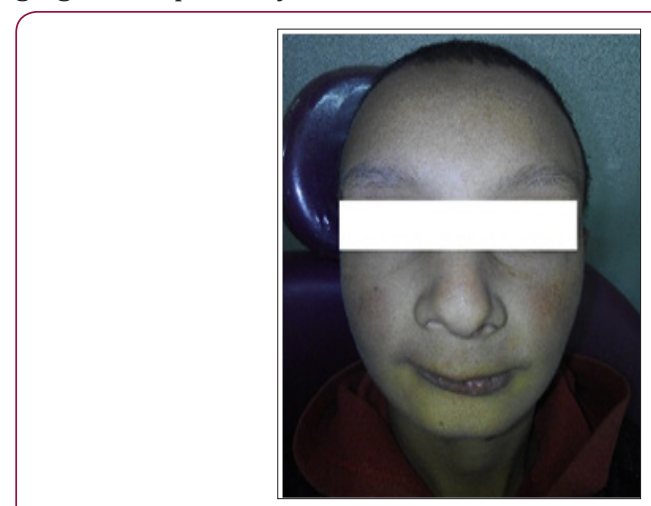

Figure 12.

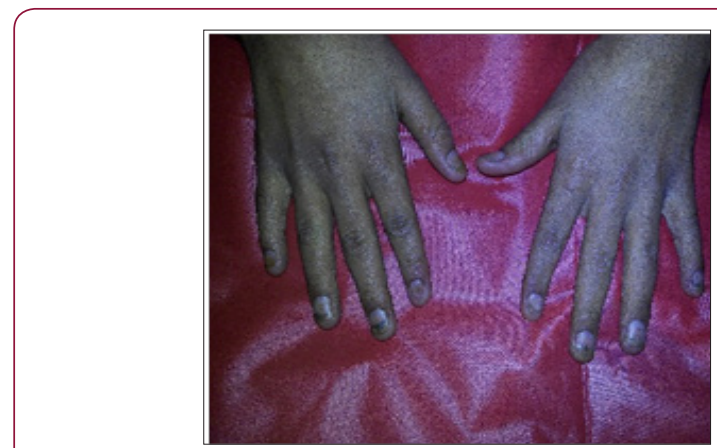

Figure 13.

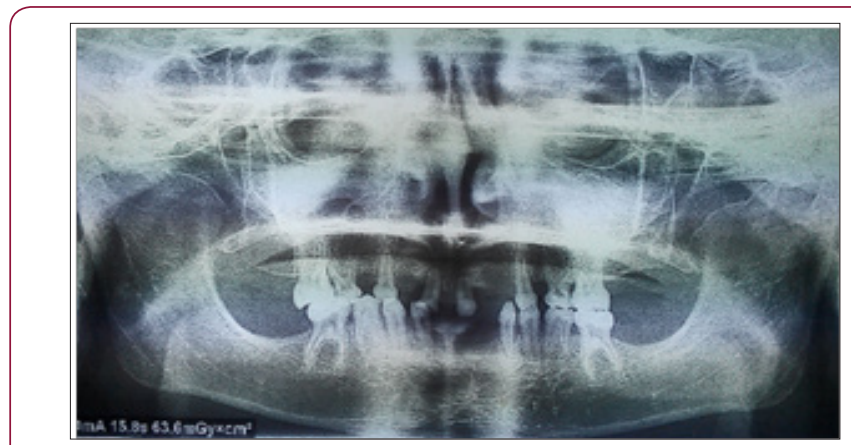

Figure 14.

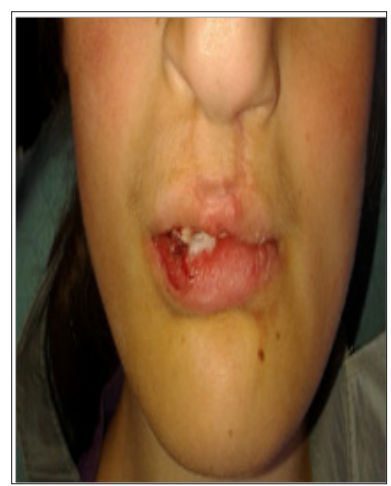

Figure 15. 


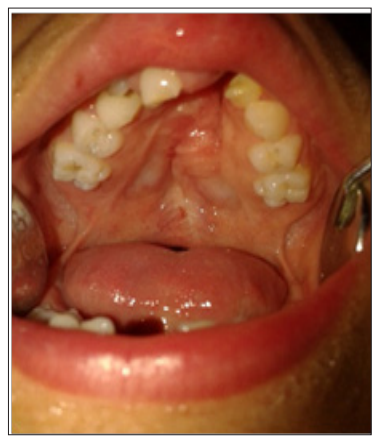

Figure 16.

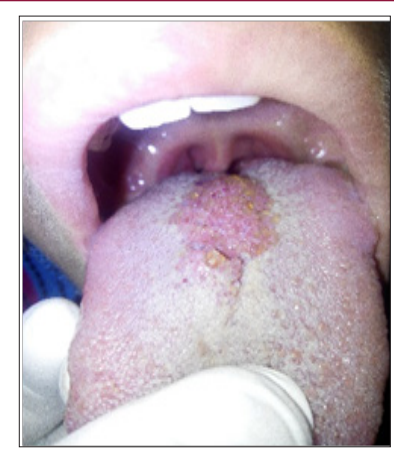

Figure 17.

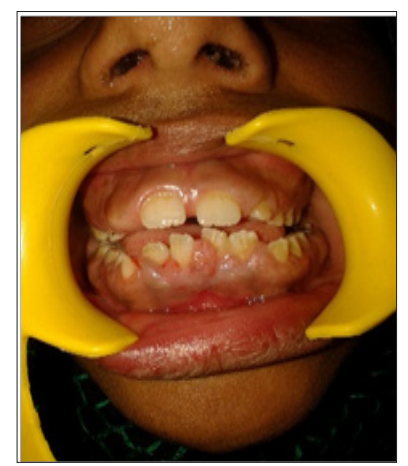

Figure 18.

\section{References}

1. American Dental Association Commission on Dental Accreditation (2013) Accreditation standards for advanced spe-cialty education programs in pediatric dentistry. Chicago Ill.

2. Callea M, Nieminen P, Willoughby CE, Clarich G, Yavuz I, et al. (2016) A novel INDEL mutation in the EDA gene resulting in a distinct X-linked hypohidrotic ectodermal dysplasia phenotype in an Italian family. J Eur Acad Dermatol Venereol.

3. (2003) Disorders of the oral cavity associated with other conditions (2003) In: Berhman RJ (Eds.). Nelson Textbook of Pediatrics. Saunders Elsevier Science.

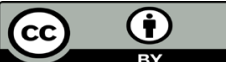

This work is licensed under Creative Commons Attribution 4.0 License

Submission Link: https://biomedres.us/submit-manuscript.php
4. Gorlin RJ (2003) Syndromes of the Head and Neck. Oxford Univerity Press, USA.

5. Brian A Moore, Brian B Burkey, MD, James L Netterville, R. Brent Butcher II, et al. (2008) Surgical Management of Minor Salivary Gland Neoplasms of the Palate. Ochsner J 8: 172-180.

6. Campbell JB, Morgan DW, Oates J, Pearman K (1989) Tumors of the minor salivary glands. Ear Nose Throat J 68: 137-140.

7. Truitt TO, Gleich LL, Huntress GP, Gluckman JL (1999) Surgical management of hard palate malignancies. Otolaryngol Head Neck Surg 121: 548-552.

8. Waldron CA, el-Mofty SK, Gnepp DR (1988) Tumors of the intraoral minor salivary glands: a demographic and histologic study of 426 cases. Oral Surg Oral Med Oral Pathol 66: 323-333.

9. Pogrel MA (1994) The management of salivary gland tumors of the palate. J Oral Maxillofac Surg 1994; 52: 454-459.

10. Ben hadj Hamida F, Jlaiel R, Ben Rayana N, Mahjoub H, Mellouli T, et al. (2005) Craniofacial fibrous dysplasia: a case report. J Fr Ophtalmol 28(8): e6.

11. Williams EF, Gannon K, Soon K (2011) The experiences of young people with epidermolysis bullosa simplex: a qualitative study. J Health Psychol 16(5): 701-710.

12. Komorowski L, Muller R, Vorobyev A, Probst C, Recke A, et al. (2013) Sensitive and specific assays for routine serological diagnosis of epidermolysis bullosa acquisita. J Am Acad Dermatol 68(3): e89-e95.

13. Momeni A, Pieper K (2005) Junctional epidermolysis bullosa: a case report. International Journal of aediatric Dentistry 15: 146-150.

14. Fine JD, Bauer EA, Briggaman RA, Carter DM, Eady RA, et al (1991) Revised clinical and laboratory criteria for subtypes of inherited epidermolysis bullosa. A consensus report by the Subcommittee on Diagnosis and Classification of the National Epidermolysis Bullosa Registry. Journal of the American Academy of Dermatology 24: 119-135.

15. Akiyama M, Shimizu H (2008) An update on molecular aspects of the non-syndromic ichthyoses. Exp Dermatol 17: 373-382.

16. Fleckman P, Di Giovanna JJ (2008) He ichthyoses: In: Fitzpatrick's Dermatology in General Medicine. (7thEdn). New York, McGraw-Hill Division 414.

17. Desai V, Das S, Sharma R (2014) A Rare Case Report-Familial Congenital Ichthyosis with Review of Literature. Dent Med Probl 51: 247-251

18. Tarjan I, Gabris K, Rozsa N (2005) Early prosthetic treatment of patients with ectodermal dysplasia: a clinical report. J Prosthet Dent 93: 419-424.

19. Vieira KA, Teixeira MS, Guirado CG, Gaviao MB (2007) Prosthodontic treatment of hypohidrotic ectodermal dysplasia with complete anodontia: case report. Quintessence Int 38: 75-80.

20. Abadi B, Herren C (2001) Clinical treatment of ectodermal dysplasia: a case report. Quintessence Int 32: 743-745.

21. Yavuz I, Ulku SZ, Unlu G, Kama JD, Kaya S, et al. (2008) Ectodermal dysplasia: clinical diagnosis. Int Dent Med Disorders 1: 1-10.

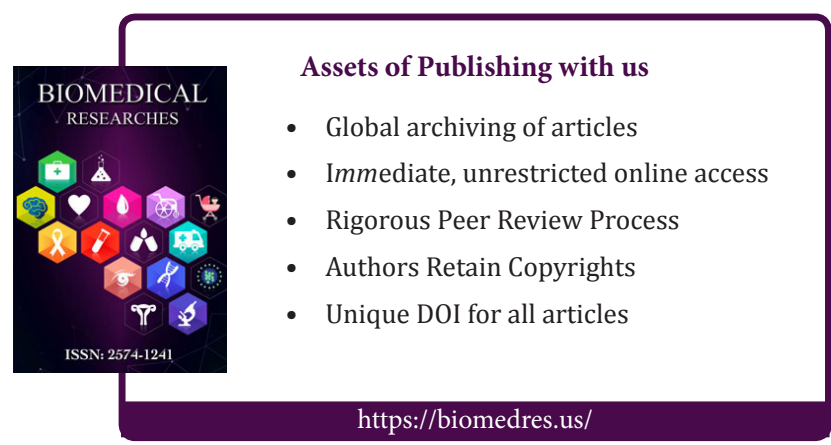

